\title{
Performance Prediction of Solar Thermal Parabolic Trough Concentrator System (STPTCS) by Enhancement of Heat Transfer
}

\author{
Y. K. Nayak ${ }^{1}$, U. K. Sinha ${ }^{2}$, Nilesh Kumar ${ }^{3}$, P. Kumar ${ }^{4}$ \\ Ph.D. Research Scholar of EED, N. I. T. Jamshedpur ${ }^{1,3}$
}

Associate Professor, EED, N. I. T. Jamshedpur ${ }^{2,4}$

\begin{abstract}
Performance prediction of STPTCS has been studied by enhancement of heat transfer rate using nanofluid, plain twisted tape and nail twisted tape inserts. Nanofluid and twisted tape inserts based STPTCS are commonly used in the area as such as industries, heating and cooling for buildings, thermal power plants, solar cooker, automobiles etc. This paper provides enhancement and performance prediction in heat transfer in absorber tube of concentrator using nanofluid and twisted tape inserts. The results obtained by simulation using $\mathrm{C}++$ program.
\end{abstract}

Keywords: Solar Thermal Parabolic Trough Collector/Concentrator System (STPTCS), Nanofluid, Twisted Tape Insert, Heat Transfer, Heating and Cooling, Friction factor.

\section{NOMENCLATURE}

A Surface area, $\mathrm{m}^{2}$

$\mathrm{C}_{\mathrm{P}} \quad$ Specific heat capacity, J/kg K

D Diameter of copper tube, $\mathrm{m}$

$\mathrm{d}_{\mathrm{n}} \quad$ Diameter of nail

f Friction factor

h Convective heat transfer co-efficient, $\mathrm{W} / \mathrm{m}^{2} \mathrm{~K}$

$h_{d n} \quad$ Head diameter of nail

I Current (A)

k Thermal conductivity, $\mathrm{W} / \mathrm{m} \mathrm{K}$

$l_{n} \quad$ Length of nail

$\mathrm{m}$ Mass flow rate, $\mathrm{kg} / \mathrm{s}$

$\mathrm{Nu} \quad$ Nusselt number

Q Heat transfer rate, W

q Heat input, $\mathrm{W}$

q" Heat flux, $\mathrm{W} / \mathrm{m}^{2}$

Re Reynolds number

$\mathrm{T}$ Temperature, $\mathrm{K}$

V Voltage, (V)

Greek symbols

P Density, $\mathrm{kg} / \mathrm{m} 3$

$\varphi \quad$ Particle volume concentration (\%)

$\mu \quad$ Dynamic Viscosity $(\mathrm{kg} / \mathrm{m} 2 . \mathrm{S})$

\section{Subscripts}

$\begin{array}{ll}\mathrm{f} & \text { Base fluid } \\ \mathrm{nf} & \text { Nanofluids } \\ \mathrm{p} & \text { Particle } \\ \mathrm{W} & \text { Water }\end{array}$

\section{INTRODUCTION}

Solar technologies can be used for a variety of application such as generation of electricity, steam generation, and sometimes air cooling and heating systems. Parabolic trough collector/concentrator has obtained wide popularity in the solar technologies. Many researchers have tested several types of heat transfer fluid in STPTCS, e.g., mineral oils, silicones, heavy aromatic oils, and molten salts. Parabolic-trough solar water heating and cooling systems have they achieved quit reasonable efficiency in converting solar radiation into useful heat of a heat transfer fluid studied by Kalogirou S. et al., [1,2,3]. A series of research have been conducted at Argonne National Laboratory of USA that the conventional fluid thermal performance could be improved using nanofluids and twisted tape inserts. The use of conventional fluids in solar collectors has very low efficiency as compared to nanofluids and twisted tape inserts.

\section{NANOFLUIDS AND TWISTED TAPE INSERTS}

The rise in effective thermal conductivity is most important in improving the heat transfer behaviour of fluids. The twisted tape inserts has also plays key role, for forced convection the heat transfer coefficient for absorbing tubes depends on many physical parameters concerned to the fluid and system through which the fluid if flowing and heating. There parameters include the properties of the fluid such as its density, viscosity, thermal conductivity and specific heat along with extrinsic system parameters such as tube diameter, length and average fluid velocity.

The effective utilization and uses of nanofluids in heat exchanges as a heat transfer fluids. There are many advantages of nanofluids in performance enhancement of the heat transfer and they are as below

- Due to nano size particles, pressure drop is minimum.

- Due to higher thermal conductivity of nano particles (fluid) will increase the heat transfer rate.

- Nanofluids will lead to lights and smaller heat exchanger.

- Heat transfer rate increases due to large surface area of nano particles in the base fluid.

- Due to above characteristics of the nanofluids it is most suitable for rapid heating and cooling. 
The twisted tapes are made of aluminium and have tape width $(w)$ of $11 \mathrm{~mm}$, tape thickness $(x)$ of $1.5 \mathrm{~mm}$ and tape length $(l)$ of $2000 \mathrm{~mm}$. the size of twisted tape may increase or decrease depending upon the design of the model for experimental or simulation purpose. The use of twisted tape for enhancement of heat transfer rate and pressure drops. A comparative study of thermal performance of an ordinary full width full length twisted tapes having modified surface configuration was represented by Monheit [4]. Dasmahapatra and Rao [5], had studied augmentation of heat transfer to viscous nonNewtonian fluids in laminar flow using full width interrupted twisted tape under the uniform wall temperature condition. Nasrin and Alim [6], investigated numerically the flow and heat transfer phenomena of different nanofluids, and compared their performances inside a solar collector, and reported that the $\mathrm{Ag} /$ water nanofluid are to be more effective in enhancing performance of heat transfer rate than that of $\mathrm{CuO} /$ water nanofluid. LalKundan and Sharma [7], have investigated the $\mathrm{CuO}$-water based nanofluid in the solar collector, it increases efficiency compared to water. By Farajollahi et al. [8], it has been investigated that the Brownian motion occurs when particle volume concentration is more than optimum value of $2 \%$. Therefore, it is expected that the heat transfer coefficient may decrease when the particle volume concentration is more than the optimum value. Suresh et al. [9] also studies that the nano particles suspended in water increases the Nusselt number even for a very low volume concentration of $0.3 \%$. In this study 0.1 and $0.3 \%$ volume concentration of nanofluid were investigated and compared with water.

Risi et al. [10] reported that the performance of solar transparent parabolic trough collector working with gas based with $\mathrm{CuO}$ and nanofluids. The maximum thermal efficiency of $62.5 \%$ for a nanofluid with an out let temperature of $650^{\circ} \mathrm{C}$ at $0.3 \%$ volume concentration was reported.

In the above several researchers were studies and carried out for solar heating system using nanofluid in turbulent regions and their results indicated a small decrease in wall temperature on the heating absorber surface can cause a great increase of the absorbing solar energy in the solar collector. In the present work the experimental heat transfer and pressure drop results of the nanofluids (water and $\mathrm{Al}_{2} \mathrm{O}_{3}$ ) passing through the receiver with twisted tape insert of STPTCS under laminar flow condition.

\section{MODEL OF THE STPTCS}

The schematic diagram of the STPTCS Fig. 1 is mainly consisted of a test section, rota meter, a pump unit, a power source and cooling water circulation system with chiller. The copper tube with $3000 \mathrm{~mm}$ long and $15 \mathrm{~mm}$ diameter like the absorber tube of PTC solar collector. The twisted tapes are made of aluminium and have tape width of $11 \mathrm{~mm}$; tape thickness of $1.5 \mathrm{~mm}$ and tape length of $2000 \mathrm{~mm}$. Nail twisted tape was obtained by punching small holes in the plain twisted tape and carefully inserts nails.
In this study, deionized water and water nano fluids at different volume concentration i.e. $0.1,0.2$ and $0.3 \%$ were used as the working fluid. Nano particles were commercial products. In the above preparation to get a uniform dispersion and stable suspension, which determine the final properties of nano fluids, the nano fluids are kept under ultrasonic vibration continuously for 6 hours.

\section{THERMO PHYSICAL PROPERTIES OF NANOFLUIDS}

The thermo-physical properties of nanofluids such as specific heat and density at different concentrations are calculated as below

$$
\begin{gathered}
\left\lfloor\left(\rho c_{p}\right)_{n f}=\phi\left(\rho_{p} c_{p, p}\right)+\rho_{w}(1-\phi) c_{p, w}\right. \\
\rho_{n f}=\phi \rho_{p}+(1-\phi) \rho_{w}
\end{gathered}
$$

The effective thermal conductivity of dilute nanofluids $\mathrm{K}_{\mathrm{nf}}$ can also be evaluated using the Maxwell model for nanofluids with volume fraction less than unity. Maxwell equation is given by

$$
\frac{K_{n f}}{K}=\frac{K_{s}+2 K+2 \phi\left(K_{s}-k\right)}{K_{s}+2 K-\phi\left(K_{s}-k\right)}
$$

\section{HEAT TRANSFER CALCULATION}

The heat flux supplied to the absorber section and energy observed by the flowing fluidis calculated from equations (4) and (5) as below:

$$
\begin{aligned}
& q=V \times I \\
& q=m c_{p}\left(T_{\text {out }}-T_{\text {in }}\right)
\end{aligned}
$$

The average heat transfer coefficient may be obtained by

$$
h=\frac{q^{\prime \prime}}{\left(\tilde{T_{w}}-\tilde{T_{b}}\right)}
$$

Where $\tilde{T_{w}}$ and $\tilde{T_{b}}$ are the mean walls and bulk fluid tanks

Where $T_{\text {wall }}$ is the 'local wall temperature evaluated at outer wall surface of tube. Now,

$$
\tilde{T}_{w}=\frac{\sum T_{w}}{11}
$$

The Nusselt Number can also be determined from the well known shah equation for laminar flow under constant heat flux boundary condition is in reasonable agreement.

$$
N_{u}=1.953\left(\operatorname{Re} \operatorname{Pr} \frac{d}{x}\right)^{\frac{1}{3}} \text { for }\left(\operatorname{Re} \operatorname{Pr} \frac{d}{x}\right) \geq 33.33
$$

The average Nusselt number is calculated as 


$$
N_{u}=h D_{i} / K
$$

The Reynolds number is given by

$$
\operatorname{Re}=\rho V D_{i} / \mu
$$

\section{PRESSURE DROP CALCULATION}

The pressure drop $\Delta \mathrm{P}$ measured across the test section under isothermal condition is used to determine the friction (f) using the relation

$$
f=\frac{\Delta P}{\frac{1}{2} \rho V^{2}} \frac{D}{L} \Rightarrow \Delta P=\frac{1}{2}\left(\rho V^{2} f L / D\right)
$$

\section{RESULT AND DISCUSSIONS}

\subsection{Heat Transfer Performances and Pressure} drop characteristics

Nusselt number of water and other volume concentration nanofluid in a plain tube with twisted tape inserts shown in figure-1 and figure-2 respectively.

\subsubsection{Effect of Reynolds Number on Nusselt Number in Plain tube and Plain Twisted Tape}

The variation of Nusselt number for water and nanofluids in plain tube and plain twisted tape are shown in Fig. 1. From the plot, it is clear that the Nusselt number slowly increases as Reynolds number increases for different volume concentration ratio and highest for volume concentration $0.3 \%$ and lowest for water.

7.1.2 Effect of Reynolds Number on Nusselt Number in Plain tube and with various Twisted Tape inserts

The variation of Nusselt number for water and nanofluids in plain tube and various plain twisted tape inserts are shown Fig. 2. The Fig. 2 shows the variation of Nusselt number with Reynolds number for water and nanofluid in plain tube and various twisted tape inserts and it is found that the variation on Nusselt number with Reynolds number is uniform in all the cases but lowest for lower volume concentration and vice versa.

\subsubsection{Effect of Reynolds number on Friction Factor in plain tube and various twisted tape}

It has been observed that the Nusselt number reasonably increased with increase in Reynolds number. The simulated result also reveal that the nail twisted tape $(\mathrm{N}-$ TT) result in a higher Nusselt number than plain twisted tape (P-TT). This can be recognized as the fact that the nails act as turbulent and give intensive mixing of nanofluid that promotes the turbulence near the tube wall surface that break the boundary layer at the surface which enhance the heat transfer and pressure gradient might be created along the radial direction while the P-TT causes swirl flow only. In addition to the above, various use of the considered in the present simulation lead to further heat transfer enhancement, increase of pressure drop and hence increase in pumping power. The reason for higher pressure drop has the dissipation of dynamic pressure of the fluid due to high viscosity loss near the tube wall. Throughout the simulated results, it is the fact that the nanofluid of $0.2 \%$ volume concentration with N-TT $(y=2)$ gave the higher volume of heat transfer compared with the other data. This is only due to increase in shear force on tube wall with the activity of larger number of nanoparticles. The maximum increase in Nusselt number was observed to be $18 \%$ when nanofluid with $0.3 \%$ volume concentration is used compared with distilled water in a plain tube.

The maximum enhancement in Nusselt number is about $22 \%$ when nanofluid with $0.3 \%$ volume concentration is used with N-TT tube. The friction factor of water and different volume concentration nanofluid in a plain tube with twisted tape insert is shown in Fig. 3 and Fig. 4 respectively.

The simulated result show the significant increase of friction factor with increase in volume concentration of nanoparticles. It is also clear that a very high friction factor is only due to use of nanofluid and twisted tape inserts, but very low friction factor in case of plain tube and water used as fluid. In general, it is obvious that the volume concentration increases the surface area that affect considerably the pressure losses in the fluid flow due to increase in disturbance of laminar layer of the boundary layer.

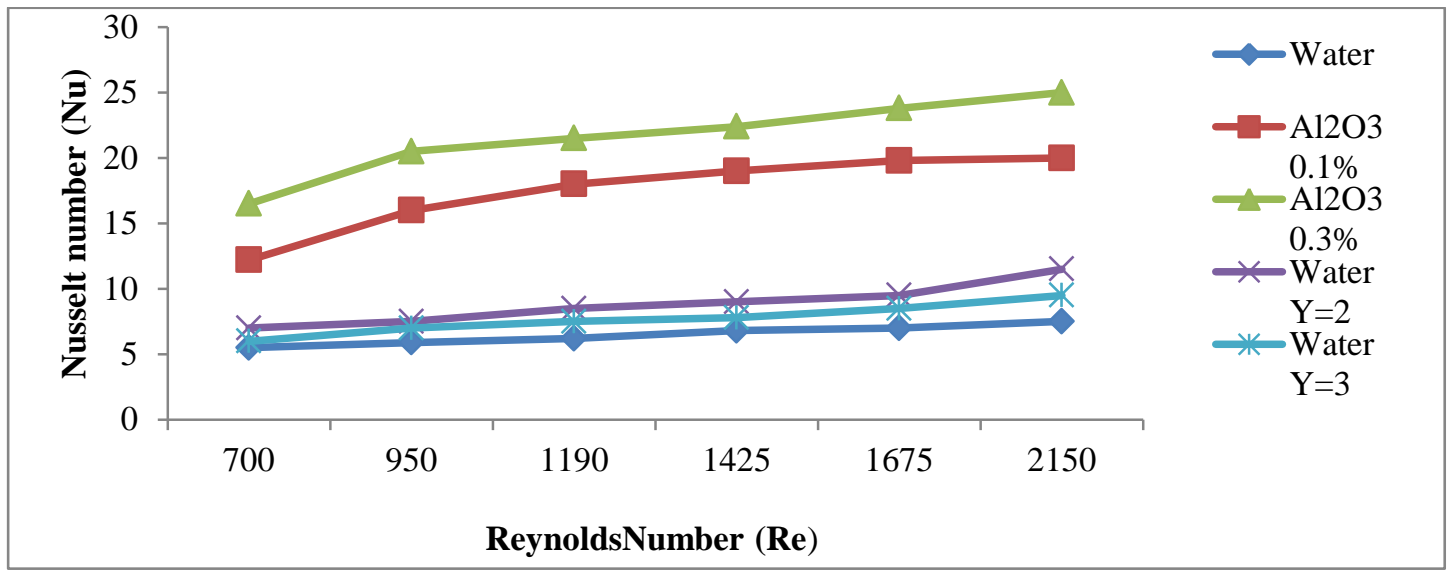

Figure 1: Variation of Nusselt number with Reynolds in plain tube and plain twisted tape 

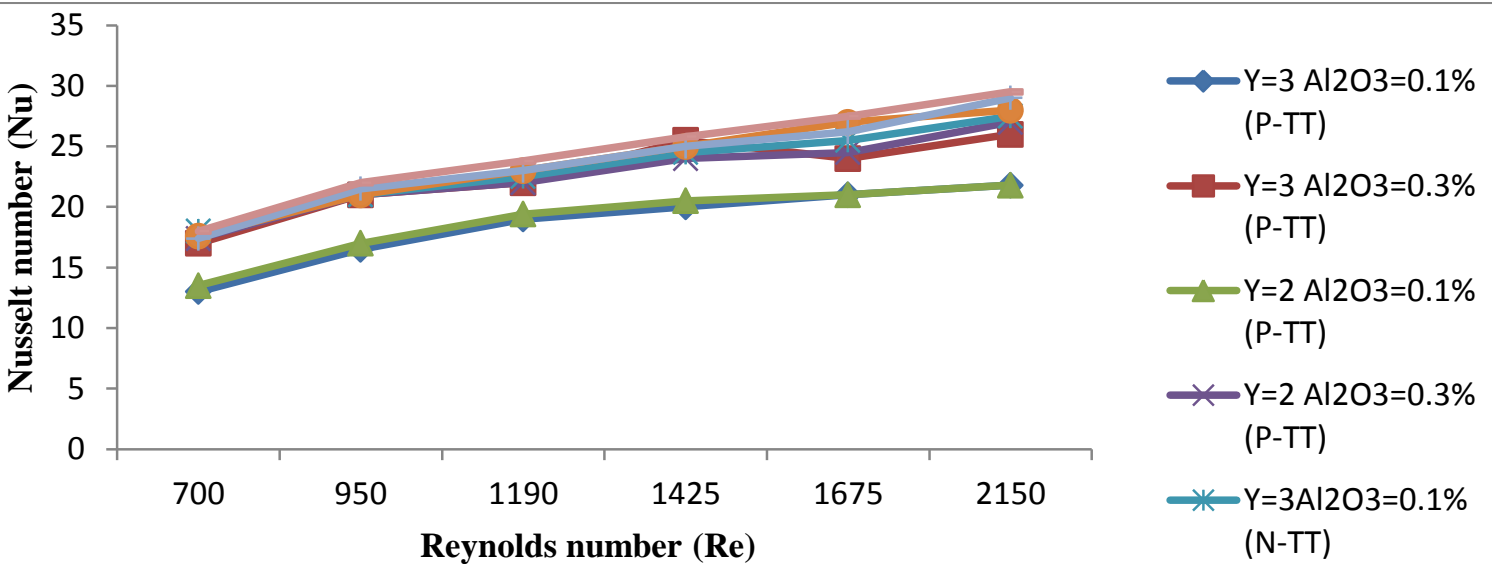

Figure 2: Variation of Nusselt number with Reynolds number in plain tube and with various twisted tapes.

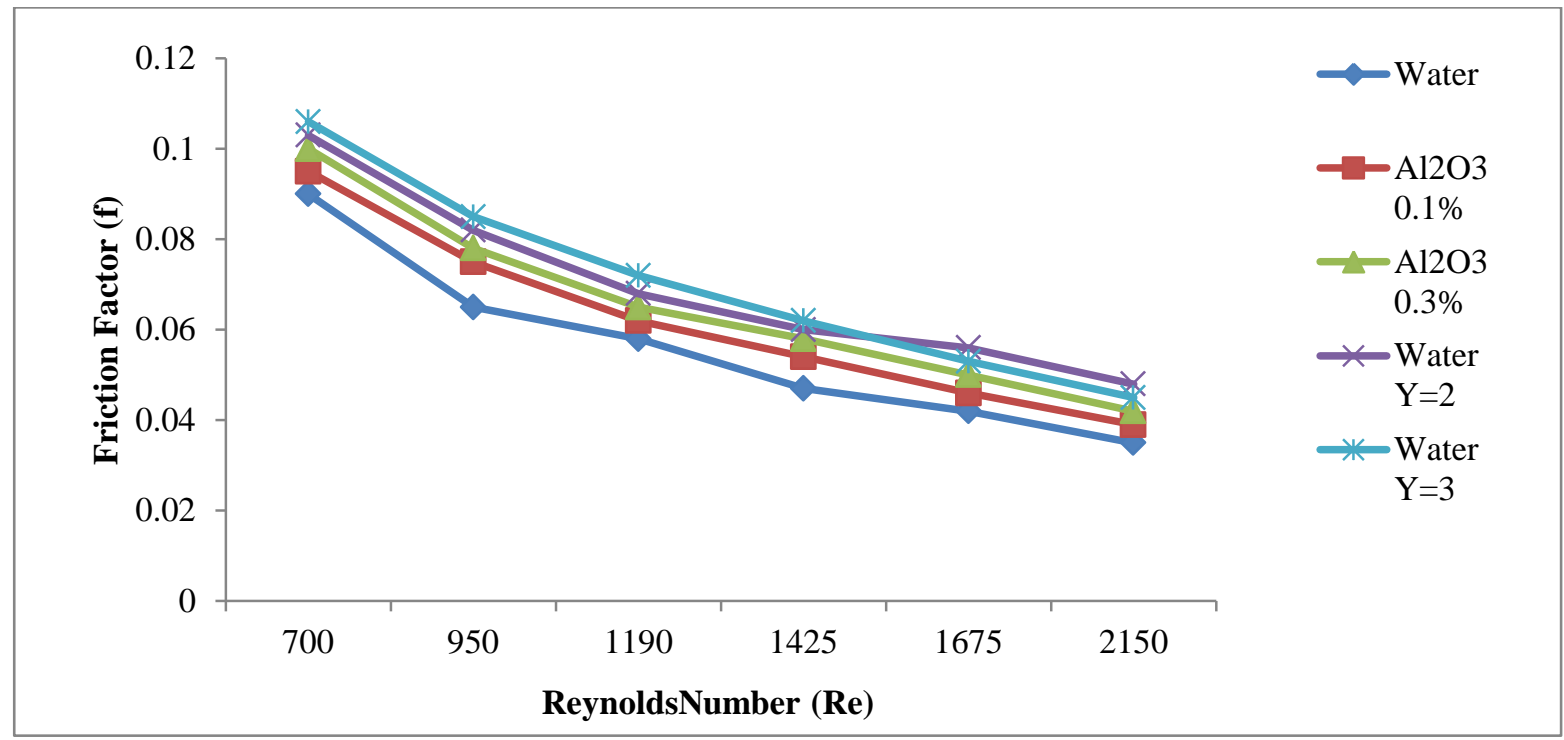

Figure 3: Variation of friction factor with Reynolds number for water and nanofluid in plain tube and plain twisted tape.

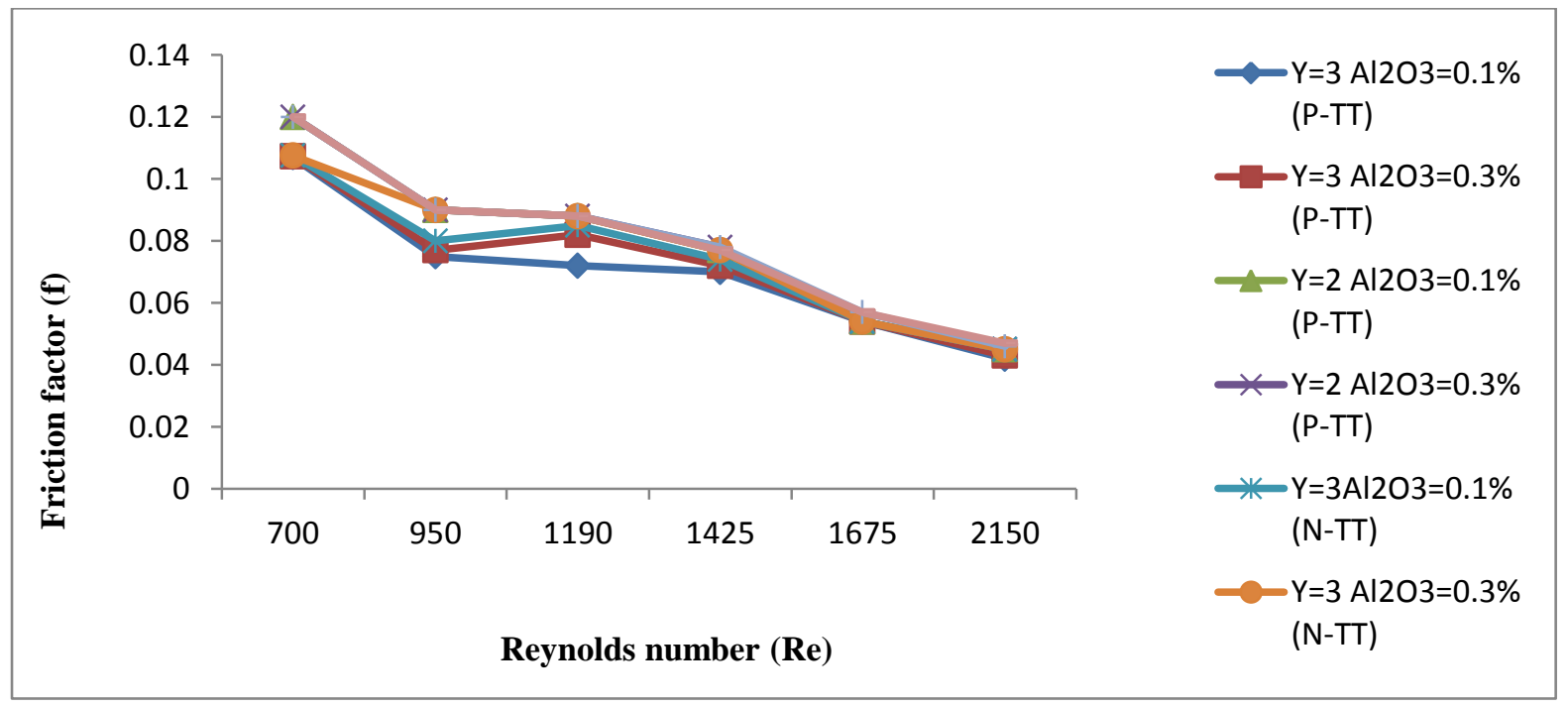

Figure 4: Variation of friction factor with Reynolds number for water and nanofluid in plain tube and with various twisted tapes 


\section{CONCLUSIONS}

The simulated results for performance prediction of STPTCS were carried out and lead to the following conclusions:

The simulation work have been carried out for heat transfer and friction factor to investigate the performance in absorber tube (on which solar radiation concentrated) for laminar flow ( i.e. for $\mathrm{R}_{\mathrm{e}}<2000$ ) using water $/ \mathrm{Al}_{2} \mathrm{O}_{3}$ nanofluid as working fluid with volume concentration of $0.1 \%$ and $0.3 \%$ with plain tube and plain twisted tape respectively. The authors conclude the following:

On the basis of simulated results, it has been concluded that

- The higher Nusselt number considerably increases with increase in the volume concentration of nanofluid.

- Heat transfer rate consequently increased due to twisted tape and varying volume concentration of nanofluid.

- The heat transfer rate increases with increase in tape twist up to a certain value.

- Friction factor initially decreases rapidly with increase in Reynolds number for various twisted tape inserts in the absorber tubes.

- Nanofluid enhances the heat transfer co-efficient with normal enhancement in pressure drop as compared to water.

- The pressure drop significantly occurs when twisted tape inserts in absorber tube due to interaction in the inertial force and pressure forces on the boundary layer.

- The most important findings of this investigation are that the use of nanofluid with $0.3 \%$ volume concentration and nail twisted tapes (N-TT) gives the higher Nusselt Number and high friction factor.

\section{REFERENCES}

1) Kalogirou S., Eleftheriou P., Lloyd S., and Ward J., 1994. Design and performance characteristics of a parabolic trough solarcollector system. Applied Energy 47: 341-354.

2) Kalogirou S., 1996. Parabolic-trough collector system for low temperature steam generation- design and performance characteristics. Applied Energy 55: 1-19.

3) Odeh S.D., Morrison G.L. and Behnia M., 1998. Modelling of parabolic through direct steam generation solar collectors. Solar Energy 62 (6): 395-406

4) Monheit. M, 1987. Experimental evaluation of the convective characteristics of tubes with twisted tape inserts, Advances in Enhanced Heat Transfer, AMSE, New York, pp. 11-18.

5) Dasmahapatra J. K, and Raja Rao M, 1991. Laminar Flow heat transfer to generalized power law fluids inside circular tubes fitted with regularly spaced twisted tape elements for uniform wall temperature condition, Fundamentals of Heat Transfer in NonNewtonian Fluids, ASME, New York, pp. 51-58.

6) Nasrin R. and M.A. Alim. 2013. Performance of nanofluids on heat transfer in a wavy solar collector. International Journal of Engineering, Science and Technology 5(3): 58-77.

7) Kundan L. and P. Sharma. 2013. Performance evaluation of a nanofluid $(\mathrm{CuO}-\mathrm{H} 2 \mathrm{O})$ based low flux solar collector. International Journal of Engineering Research 2(2): 108-112.

8) Farajollahi B., EtemadS.Gh. And Hojjat M., 2010. Heat transfer of nanofluids in a shell and tube heat exchanger. International Journal of Heat and Mass Transfer 53(1-3): 12-17.

9) Suresh S., Chandrasekhar M. and Selvakumar P., 2012. Experimental studies on heat transfer and friction factor characteristics of $\mathrm{Al} 2 \mathrm{O} 3$ /water nanofluid under laminar flow with spiraled rod inserts. International Journal of Nanoparticles 5(1): 37 55.

10) De Risi A., Milanese M. and Laforgia D., 2013. Modeling and Optimization of Transparent Parabolic Trough Collector based on gas phase nanofluid. Renewable Energy 58: 134-139. 